ORIGINAL ARTICLE

AFRICAN JOURNAL OF CLINICAL AND EXPERIMENTAL MICROBIOLOGY

AJCEM/200976/21018

COPYRIGHT 2010

AFR. J. CLN. EXPER. MICROBIOL 11(3): 146-149
SEPTMBER $2010 \quad$ ISBN 1595-689X VOL 11(3)

-http://www.ajol.info/journals/ajcem

\title{
STUDIES ON BACTERIAL INFECTIONS OF DIABETIC FOOT ULCER
}

\author{
J.vimalin Hena, Lali Growther. Department of Microbiology, Hindustan College of Arts \&Science, Coimbatore. India
}

\begin{abstract}
Microbial study for aerobic organisms from 100 cases of diabetic foot ulcers was carried out to determine the etiological agents and their antibiogram. Polymicrobial infection was observed in all the cases. The most frequently isolated aerobic organisms were Staphylococcus aureus and Pseudomonas aeruginosa. Antimicrobial sensitivity pattern of the isolates were done in which imepenem was found to be effective. Imipenem belongs to the B lactam group of new generation antibiotics.
\end{abstract}

Key words: Diabetes, Imipenam, Foot ulcer.

\section{INTRODUCTION}

Diabetes is a metabolic disorder of the endocrine system which plagues approximately 17 million people nationwide. Each year over 700,000 new cases are diagnosed; 12,000 to 14,000 of which are children, teenagers and young adults, while this life threatening disease can be controlled. Diabetes is often accompanied by serious complications, and still today there is no cure (1). By 2010 it is predicted that it will affect 239 million people world wide.

Fifteen per cent of people with diabetes will develop a foot ulcer at some time during their life, and $85 \%$ of major leg amputations begin with a foot ulcer (2). Poorly controlled diabetes is prone to skin infections because elevated blood sugar reduces the effectiveness of bacteria fighting cells. Carbuncles, boils, and other skin infections may be hazardous if not properly treated. Even a small cut may progress to a deep, open sore, called an ulcer (3). In most cases ulceration is a consequence of the loss of protective sensation that is, the loss of awareness of trauma that can cause the breakdown of the skin.

The organisms that occur on foot infections are generally Staphylococcus aureus and Streptococcus pyogens arising from the patients' own skin and Enterococci from bowel. Among the Gram positive aerobes Staphyloccoci are more prevalent. Many of these microorganisms are developing resistance to commonly used antibiotics largely due to their indiscriminate use. The present study was undertaken to determine the microbiology of the diabetic foot ulcers and the antimicrobial sensitivity pattern of the isolates.

MATERIALS AND METHODS: A total number of 100 diabetic patients with foot ulceration were studied during the period of December 2005to Feburary2006. The cases were from Government hospital Coimbatore. Swabs were collected from ulcers that were macroscopically examined and classified based on Wagner's method of evaluation (3, 4). Swabbing was done on slouphy or inflammmed tissue as bacteria tend to present in greater number in these areas. From each patient two swabs were collected. The sterile cotton were moistened with sterile saline before collecting the specimens. One of the swabs was used for the isolation of bacteria. The other swab was used for wet mount microscopy. For the isolation of bacteria the media used were blood agar, and Mac Conckey agar, which were incubated at $37 \mathrm{C}$ for 24 hours. The organisms isolated were subjected to antibiotic susceptibility testing on MullerHinton agar using Kirbey-Bauer disc diffusion method (5).

RESULTS Of the total 100 diabetic foot patients studied 69 were males and 31 were females, the male: female ratio being 2:1. Their ages ranged from 35 years to 85 years with an average of 58 years. The maximum number of patients having diabetic foot infections belonged to the age group of 56-65 years, the cases was with diabetes ellitus for more than a decade. 
TABLE 1: AEROBIC BACTERIAL ISOLATES

\begin{tabular}{|l|c|c|}
\hline Culture isolate & Number of isolates & percer \\
\hline S.aureus & 47 & 42.3 \\
\hline C.koseri & 3 & 2.70 \\
\hline E.coli & 17 & 15.3 \\
\hline K.pneumoniae & 10 & 9.0 \\
\hline Ps.aeruginosa & 27 & 24.3 \\
\hline P.vulgaris & 7 & 6.3 \\
\hline
\end{tabular}

Of the 100 patients, 48 patients had some other complications, such as peripheral vascular disease, neuropathy, nephropathy, retinopathy, cataract, ischaemic heart disease or hypertension along with diabetes mellitus. Peripheral neuropathy

TABLE 2: ANTIBIOTIC SENSITIVITY PATTERN OF THE AEROBIC GRAM POSITIVE ISOLATES

\begin{tabular}{|l|l|}
\hline \multicolumn{1}{|c|}{ Antibiotics } & $\begin{array}{l}\text { S.aureus } \\
(\mathrm{n}=47) \text { number of } \\
\text { sensitive } \\
\text { strains(percentag }\end{array}$ \\
\hline Amikacin(30 mcg) & $19(40.4)$ \\
\hline Cloxacillin(30 mcg) & $11(23.4)$ \\
\hline Cefepine(30 mcg) & $11(23.4)$ \\
\hline Chloramphenicol(30 mcg) & $33(70.2))$ \\
\hline Ciprofloxacin(25 mcg) & $12(25.5)$ \\
\hline Cotrimoxazole(25 mcg) & - \\
\hline Gentamycin(10 mcg) & $18(38.2)$ \\
\hline Pencillin(100 mcg) & $2(4.2)$ \\
\hline Tetracyclin(30 mcg) & $5(10.6)$ \\
\hline Gatifloxacin(5 mcg) & $30(63.8)$ \\
\hline Vancomycin(30 mcg) & $14(29.7)$ \\
\hline
\end{tabular}

has a central role and is present over $80 \%$ of diabetic patients with foot lesions

From the 100 patients studied, aerobic bacteria in the pure form were isolated in all the cases in which 47 were $S$. aureus, 3 were C. koseri, 17 were E. coli, 10 were K. pneumoniae, 27 Ps. aeruginosa, 7 were P. vulgaris.

TABLE 3a: ANTIBIOTIC SENSITIVITY PATTERN OF THE AEROBIC GRAM NEGATIVE ISOLATES

\begin{tabular}{|c|c|}
\hline Antibiotics & $\begin{array}{c}\text { S. aureus (\%) } \mathbf{n}=37 \\
\text { Number of } \\
\text { Sensitive Strains }\end{array}$ \\
\hline Amikacin (30mcg) & $19(70.3)$ \\
\hline Cloxacillin (30mcg) & $11(40.7)$ \\
\hline Cefepine (30mg) & $11(40.7)$ \\
\hline Chloramphenicol & $23(85.1)$ \\
\hline $30 m c g$ & $12(44.4)$ \\
\hline Ciprofloxacin (25mcg) & - \\
\hline Cotrimoxazole(25mcg) & $18(66.6)$ \\
\hline Gentamycin(10mcg) & $2(7.4)$ \\
\hline Penicillin(100mcg) & $5(18.5)$ \\
\hline Tetracyclin(30mcg) & $20(74)$ \\
\hline Gatifloxacin(5mcg) & $14(51.8)$ \\
\hline Vancomycin(30mcg) & \\
\hline
\end{tabular}


TABLE 3b: ANTIBIOTIC SENSITIVITY PATTERN OF AEROBIC GRAM NEGATIVE BACTERIA

\begin{tabular}{|c|c|c|c|c|c|}
\hline Antibiotics & $\begin{array}{l}\text { E.coli } \\
\mathrm{n}=17\end{array}$ & $\begin{array}{c}\text { C. } \text { koseri } \\
\mathrm{n}=3\end{array}$ & $\begin{array}{c}\text { K.pneumoniae } \\
\mathbf{n}=10\end{array}$ & $\begin{array}{c}\underline{P . v u l g a r i s} \\
\mathrm{n}=7\end{array}$ & $\begin{array}{c}\text { Pseudomonos } \\
\mathbf{n}=27\end{array}$ \\
\hline Ciprofloxacin (5mcg) & $9(52.9)$ & $3(100)$ & $5(50)$ & 5 (71.4) & $6(22.2)$ \\
\hline Ceftazidine (30mcg) & $11(64.7)$ & $2(50)$ & $3(30)$ & 5 (71.4) & $11(40.7)$ \\
\hline Piperacillin(100mcg) & $12(70.5)$ & $3(100)$ & $5(50)$ & 4 (57.1) & $22(81.48)$ \\
\hline Ceftoxine $(30 \mathrm{mcg})$ & $10(58.8)$ & $3(100)$ & $2(20)$ & $2(28.5)$ & 3 (11.1) \\
\hline Amikacin (30mcg) & $10(58.8)$ & $3(100)$ & $8(80)$ & $4(57.1)$ & $13(48.14)$ \\
\hline Imipenam(10mcg) & $16(94.1)$ & $3(100)$ & $10(100)$ & 7 (100) & $27(100)$ \\
\hline Chloramphenicol (30mcg) & $6(35.2)$ & $2(50)$ & 7 (70) & - & $8(29.6)$ \\
\hline Gentamycin(10mcg) & $10(58.8)$ & - & $6(60)$ & $5(71.4)$ & $4(14.8)$ \\
\hline Gatifloxacin (5mcg) & $12(70.5)$ & $3(100)$ & $8(80)$ & 5 (71.4) & $17(62.96)$ \\
\hline Cotrimoxazole (25mcg) & 2 (11.7) & - & - & - & - \\
\hline Tetracyclin(30mcg) & $2(11.7)$ & - & - & - & $2(74.07)$ \\
\hline
\end{tabular}

Over $63.8 \%$ strains of S.aureus were sensitive to gatifloxacin. Only $25.5 \%$ of strains were sensitive to ciprofloxacin (Table 2). While E. coli was highly sensitive to the antibiotics tested, Pseudomonas was highly resistant to them (Table 3 ).

\section{DISCUSSION}

The presence of S. aureus, Proteus species and other aerobic gram negative bacilli in septic complications of infected diabetic feet have been reported in various studies.

The infections are usually polymicrobial in nature, caused by aerobic Gram- positive S. aureus, and by Grampositive bacilli like E. coli, Klebsiella species and Proteus (5). In the present study S. aureus (43.2\%) was predominantly isolated. As regards the aerobic Gram negative bacilli, Pseudomonas aeruginosa $(24.3 \%)$ E. coli $(15.3 \%) \quad$ C. koseri $(2.7 \%)$ P. vulgaris(6.3\%) and K. pneumoniae(9\%) were the common organisms isolated. When testing the susceptibility to fluroquinolones, individual drugs must be included, as susceptibility to one drug cannot be taken as evidence of susceptibility to other fluroquinolones .

Among the 17 isolates of E. coli quinolone and cephalosporin group of antibiotics showed a higher sensitivity than to commonly used chloramphenicol. The 3 isolates of C.koseri were found to be sensitive to all major groups of antibiotics except to tetracycline so further analysis of its prevalene of resistance is required.10 isolates of K.pneumoniae showed marked difference in their sensitivity pattern to the quinolone group of antibiotics there was a pattern of resistence to ciprofloxacin and sensitivity to gatifloxacin .The 7 isolates of Proteus were resistant to major group of antibiotics but a high sensitivity pattern was shown towards to gatifloxacin. In Pseudomonas the total isolates were resistant to the most commonly used antibiotics like ciprofloxacin, ceftoxime, amikacin, chloramphenicol and tetracycline,but all were sensitive to the beta lactum antibiotic imipenem.

In this study all the Gram negative isolates were susceptible to carbapenem beta lactum antibiotic imipenem, which is resistant to inactivation by most bacterial beta lactamases and so it has the widest spectrum of antibacterial activity. Imipenem should therefore be used as a monothreraphy against polymicrobial infections in difficult gram negative infections. It produces a response rate comparable to that of third generation cephalosporins.

\section{ACKNOWLEDGEMENT}

We thank Dr. Parimala and Mr. Ramanathan for their guidance and moral support.

\section{REFERENCES}

1. Lipsky, B.A., Pecoraro, R.E. Larson S.A., Hanley, M.E. Ahroni, J.H (1990) Outpatient management of uncomplicted lower -extremity infection in diabetic patients Arch. Intern. Med. 150: (790-797). 
2. Ramani, A., Ramani, R., Shivananda, P.G and Kundaje, G.N(1991). Bateriology of diabetic foot ulcers. Indian. J pathol . Micronbiol. 34: (81-87)

3. Boulton., AJ(2000). The diabetic foot: a global view. Diabetes Metab Res Rev:16

4. Pathare, N.A., Bal,A., Talvalkar, G.V.and Antani D.V(1998). Diabetic foot infections a study of microorganisms associated with the different Wagner grades. Indian J Pathol Microbiol 41(4):437-441.
5. Prabhakar P Rao and Hira J(1981): Bacterilogical study of diabetic foot ulcers. Trop.geogr. Med. 33: 249-252. 6. Anandhi.c., Alaguraj and Natrajan(2004).

Bacteriology of Diabetic foot: lesions. Indian Journal of microbiology.volume:22,Issue:3(175-178).

7..Sally.M.and and Marshell(2004).Diabetic Medicine. Journal of Diabetes U.K.volume 21:Issue 7pp(37-87) 